\title{
ICH RF SYSTEM DATA ACQUISITION AND REAL TIME CONTROL USING A MICROCOMPUTER SYSTEM
}

\author{
by \\ W.P. CARY, J.A. ALLEN, R.I. PINSKER, \\ and C.C. PETTY
}

This is a preprint of a paper to be presented at the 15th IEEE Symposium on Fusion Engineering, October 11-15, 1993, Cape Cod, Massachusetts, and to be printed in the Proceedings.

Work supported by

U.S. Department of Energy

Contract DE-AC03-89ER51114

GENERAL ATOMICS PROJECT 3466

OCTOBER 1993

\section{GENERAL ATOMICS \\ M:Prop}




\title{
ICH RF SYSTEM DATA ACQUISITION AND REAL TIME CONTROL USING A MICROCOMPUTER SYSTEM
}

\author{
W.P. Cary, J.A. Allen, R.I. Pinsker, and C.C. Petty \\ General Atomics \\ P.0. Box 85608, San Diego, California 92186-9784
}

\begin{abstract}
On the basis of the rapidly increasing power, speed, and decreasing cost of the personal computer (microcomputer) it was felt that a real time data acquisition and control system could be configured quickly and very cost effectively. It was further felt that by using a high level or object-oriented programming language that considerable time and expense could be saved and at the same time increase system flexibility. This paper will attempt to address the desired system requirements and performance for both the control of the high power transmitters and for the data acquisition and presentation of the information.
\end{abstract}

\section{INTRODUCTION}

A 4 MW Fast Wave Current Drive (FWCD) upgrade is being installed on DIII-D [1]. This upgrade will include the use of computer control for data acquisition transmitter control and to some extent, real time control of various key transmitter parameters. The heart of the system will be a Sun Microsystems SPARCstation 10-30 and assorted VXI hardware. It is hoped that some real time control can be accomplished with this minimum hardware configuration but a dedicated 030 processor will probably be necessary in the future to handle the more sophisticated real time control functions. Fig. 1 gives an overview of the intended hardware configuration. In an attempt to reduce the development time and associated costs the use of a high level language (LabVIEW) will be used for software development. Since this language was developed with the engineer in mind, it is hoped that the normally long development and debugging time can be reduced significantly and, furthermore, program refinements can be accomplished by the transmitter engineer instead of having to wait for a systems programmer to become available.

\section{SYSTEM REQUIREMENTS}

As envisioned, the system will be composed of three types of control functions. All control types even though they have their own timing specifications will sitl have the ability to communicate with each other. The bulk of the control functions can be classified as slow response functions. These include many of the interlock functions as well as many of the data acquisition channels. Slow in this case will be considered to be in the tens of milliseconds, or used only for viewing information. These tend to be voltage and current signals that will be viewed after the pulse and are normally safety interlocked as part of the transmitter hardware or are used primarily for tuning or adjustment purposes. The interlocks mentioned will tend to be trausmitter conditioned interlocks such

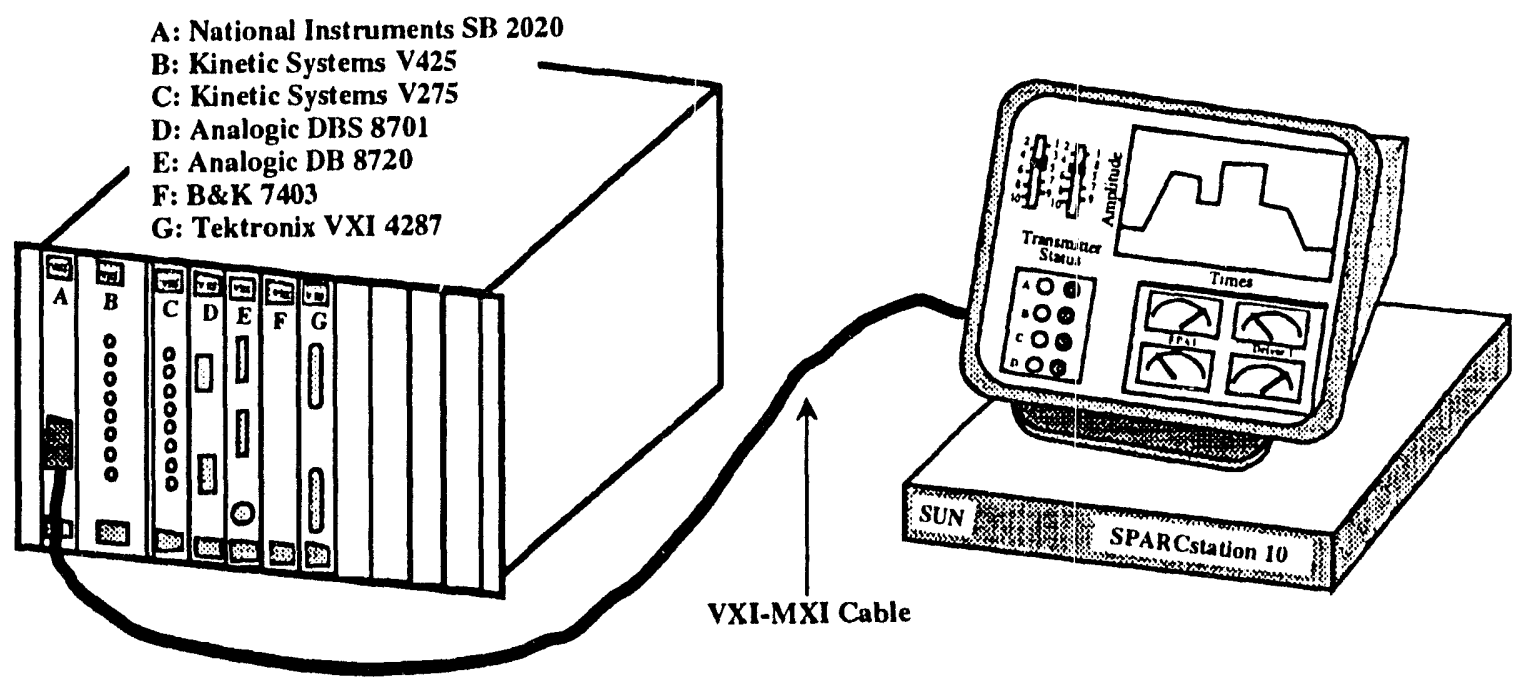

Fig. 1 Computer hardware.

Mamuscript received October 12, 1993. This is a report of work sponsored by the U.S. Department of Energy under Contract No. DE-AC03-89ER51114. 
as door interlocks or limit switches. Here again, their status will be recorded on the computer but their real safety function will be managed as part of the built in transmitter hardware control system.

The next level in the speed sense will be those functions requiring actions in the range of 1 to $10 \mathrm{msec}$. These could tend to be items such as frequency or phase control which are needed to compensate for slow changes in plasma position or density.

Power leveling could also be included in this group but will probably require faster control and response if it is to be used to protect the antenna and transmission line from arcing damage. For the purpose of this paper, the fast response functions need to respond to events in less than $1 \mathrm{msec}$ and are those items that are needed to protect hardware be it the transmitter, transmission line, or the antennas.

To support the fast control functions, data will be the need to be collected and transferred at rapid rates so that analysis and action can be taken in the appropriate time. Data transfer through the VXI-MXI bus will first be tried. This will allow the use of the SPARCstation memory and processor. If it is found that the required speed is not available, a VXI-based $68030 \mathrm{CPU}$ will have to be incorporated along with additional VXI memory. A similar control system is now in use at DIII-D for plasma control using a VME based Intel i860 [2].

\section{HARDWARE}

A minimal hardware configuration has been chosen to first determine the feasibility of the system. Later this system will be modified or augmented as necessary to meet system performance requirements. It is hoped that the initial hardware will be sufficient for dummy load and control testing and that any shortcomings will become evident early so that changes may be made without too much loss in time or additional hardware costs.

A VXI format was chosen due to its flexibility along with its proven track record in the rf component testing environment. Since LabVIEW was chosen as the programming language, it was decided to use the National Instruments VXI controller card along with their MXI to VXI interface components. Table I shows the various VXI hardware and their specifications.

\section{DATA ACQUISITION AND CONTROL}

There will be approximately 35 channels of analog information to be recorded along with an additional 20 or more status type signals. Most of the status signals will be treated as slow signals with their status only being noted if an event occurs. The use of a time stamp comparator board will help keep the data level down by only generating an interrupt if an event takes place. The board will also time stamp the channel(s) that faulted. This information can be used in troubleshooting the sequence of events leading to the event. All analog signals will be digitized for possible display and archiving
Table I

VXI Components

\begin{tabular}{|c|c|c|}
\hline Module No. & Description & Manufacturer \\
\hline VX1400A & $\begin{array}{l}\text { 13-slot VXI mainframe } \\
\text { \& power supply }\end{array}$ & Tektronix \\
\hline 7403 & $\begin{array}{l}\text { VIX memory module, } \\
16 \text { Mbyte }\end{array}$ & Bruel \& Kjaer \\
\hline $\mathrm{VX} 4287$ & 32 channel A/D module & Tektronix \\
\hline V275-MB11 & $\begin{array}{l}8 \text { channel, } 12 \text { bit D/A } \\
\text { converter }\end{array}$ & Kinetic Systems \\
\hline V425-MB11 & $\begin{array}{l}8 \text { channel, } 12 \text { bit } \\
\text { transient recorder }\end{array}$ & Kinetic Systems \\
\hline DBS-8701 & $400 \mathrm{kHz}, 16$ bit digitizer & Analogic \\
\hline DBS-8720 & 32 channel MUX & Analogic \\
\hline SB-2020 & VXI slot $A$ controller card & National Instruments \\
\hline
\end{tabular}

if necessary. With the use of LabVIEW's ability to mix control with display, we will use the Sun and LabVIEW combination to replace our normal oscilloscopes for system performance display. Software will also be used to replace the numerous analog modules now used for transmitter control. Pulse width and amplitude are the two that will be implemented first. Later, frequency control and real time tuner control are hoped to be implemented. A set of fast digitizers with FIFO anc extra memory boards may be used to make some of the real time control possible. There is presently a plasma control system based on an older version of the SUN SPARCstation2 that is capable of performing many of the necessary control functions for real time plasma shape control on DIII-D [3]. This system uses inhouse developed software to meet the much higher processing demands but it is felt that the experience learned there will help in the speedy development of this system especially on the hardware side.

The $\sim 10$ min intervals between tokamak shots will also be put to good use by displaying any of the analog signals or for setting up the transmitter for the next shot. One function in particular will be used until faster tuning elements for the matching system can be developed and that is running the existing TOONS program based on the data gathered on the previous shot and commanding the phase shifters and stub tuners to the new computed positions [4]. This task is now only partially done by computer with the data entry and motor drive commands being done manually. When this is implemented it will give us the ability to change frequency and or antenna phasing between shots automatically.

\section{SUMMARY}

The system described should be capable of performing most of the desired objectives with little change from the basics presented here. Only the real time control systems need to be investigated further. With the use of a dedicated VXI processor, even the real time control functions should be able to be performed with little trouble. The use of the high level programming language of 
LabVIEW along with the ever increasing power of the small microcomputers or work stations makes the use of them in real time applications a reality and easy to implement.

\section{REFERENCES}

[1] J.S. deGrassie, R.I. Pinsker, W.P. Cary, R.W. Callis, R. O'Neill, D.B. Remsen, and W. Ferguson, " $4 \mathrm{MW}$ upgrade of FWCD on DIII-D," this symposium.
[2] J.R. Ferron and E.J. Strait, "Real time analysis of tokamak discharge parameters," Rev. Sci. Instrum. vol 63, p. 4799, 1992.

[3] J.R. Feston, "A high speed data acquisition and processing system for real time data analysis and control," Rev. Sci. Instrum. vol. 63, p. 5464, 1992.

[4] R.I. Pinsker, M.J. Mayberry, C.C. Petty, W.P. Cary, J. Pusl, D. Remsen, et al., " $30.60 \mathrm{MHz}$ FWCD system on DIII-D: power division, phase control and tuning for a four-element antenna array," in Proc. 14th IEEE/NPSS Symp. on Fusion Engineering, San Diego, vol. I, p. 115, 1991. 
